\title{
Corrigendum: Pleiotropic Meta-Analyses of Longitudinal Studies Discover Novel Genetic Variants Associated with Age-Related Diseases
}

\author{
Liang He*, Yelena Kernogitski, Irina Kulminskaya, Yury Loika, Konstantin G. Arbeev, \\ Elena Loiko, Olivia Bagley, Matt Duan, Arseniy Yashkin, Svetlana V. Ukraintseva, \\ Mikhail Kovtun, Anatoliy I. Yashin and Alexander M. Kulminski
}

Biodemography of Aging Research Unit, Social Science Research Institute, Duke University, Durham, NC, United States

Keywords: pleiotropic analysis, age-related traits, CVDs, genetic association study, mediation analysis, age-dependent effects

\section{A corrigendum on}

Pleiotropic Meta-Analyses of Longitudinal Studies Discover Novel Genetic Variants Associated with Age-Related Diseases

by He, L., Kernogitski, Y., Kulminskaya, I., Loika, Y., Arbeev, K. G., Loiko, E., et al. (2016). Front. Genet. 7:179. doi: 10.3389/fgene.2016.00179

In the original article, we included a supplementary material "Presentation 1.PDF." The original purpose of this supplementary material is to provide readers with more explanation of the marginal

\section{OPEN ACCESS}

Edited and reviewed by:

Frontiers in Genetics,

Frontiers Media SA, Switzerland

*Correspondence:

Liang $\mathrm{He}$

lianghe@mit.edu

Specialty section:

This article was submitted to

Genetics of Aging,

a section of the journal

Frontiers in Genetics

Received: 29 October 2017 Accepted: 15 December 2017

Published: 12 January 2018

Citation:

He L, Kernogitski Y, Kulminskaya I, Loika Y, Arbeev KG, Loiko E, Bagley O,

Duan M, Yashkin A, Ukraintseva SV,

Kovtun M, Yashin Al and Kulminski AM

(2018) Corrigendum: Pleiotropic

Meta-Analyses of Longitudinal Studies

Discover Novel Genetic Variants

Associated with Age-Related

Diseases. Front. Genet. 8:226.

doi: 10.3389/fgene.2017.00226 structural model (MSM) we used for mediation analysis. However, we made some mistakes in the mathematical expression in the supplementary material which can be misleading. For more details about the model, it would be better for readers to directly refer to the three cited articles in which the model is proposed. Thus, we think that this supplementary material is inaccurate and redundant, and should be removed. Note that this supplementary material was only for illustrative purpose and does not affect any results in the article. So removing it will not change anything else in the article. In addition, we should have added in the subsection "Pleiotropic Meta-Analysis" the following statement "We checked the multivariate normality assumption for these summary statistics under the null hypothesis using the Henze-Zirkler test (Henze and Zirkler, 1990), and found no evidence of violation of the assumption." This statement ensures the validity of the omnibus test for our analyses.

The authors apologize for this error and state that this does not change the scientific conclusions of the article in any way.

The original article has been updated.

\section{REFERENCES}

Henze, N., and Zirkler, B. (1990). A class of invariant consistent tests for multivariate normality. Comm. Statist. Theory Methods 19, 3595-3617. doi: 10.1080/03610929008830400

Conflict of Interest Statement: The authors declare that the research was conducted in the absence of any commercial or financial relationships that could be construed as a potential conflict of interest.

Copyright @ 2018 He, Kernogitski, Kulminskaya, Loika, Arbeev, Loiko, Bagley, Duan, Yashkin, Ukraintseva, Kovtun, Yashin and Kulminski. This is an open-access article distributed under the terms of the Creative Commons Attribution License (CC $B Y)$. The use, distribution or reproduction in other forums is permitted, provided the original author(s) or licensor are credited and that the original publication in this journal is cited, in accordance with accepted academic practice. No use, distribution or reproduction is permitted which does not comply with these terms. 